\title{
XI. The effect of temperature on the ionization produced in gases by the action of Röntgen rays
}

\section{R.K. McClung M.A. B.A.}

To cite this article: R.K. McClung M.A. B.A. (1904) XI. The effect of temperature on the ionization produced in gases by the action of Röntgen rays, Philosophical Magazine Series 6 , 7:38, 81-95, DOI: $10.1080 / 14786440409463093$

To link to this article: http://dx.doi.org/10.1080/14786440409463093

册 Published online: 08 Jun 2010.

Submit your article to this journal $\lceil\pi$

Џ Article views: 3

Q View related articles $\asymp$ 
LONDON, EDINBURGH, AND DUBLIN

\title{
PHILOSOPHICAL MAGAZINE
}

\author{
AND \\ JOURNAL OF SCIENCE. \\ [SIXTH SERIES.] \\ FEBRUARY 1904 .
}

XI. The Effect of Temperature on the Ionization produced in Gases by the Action of Röntgen Rays*. By R. K. McClung, M.A. (McGill), B.A. (Cantab.), Trinity College, Cambridge, "1851 Exhibition Science Scholar" †.

\section{Introduction.}

$\mathrm{D}$ URING the course of an investigation on the effect of temperature on the rate of recombination of gaseous ions, the results of which appeared in a previous paper $\ddagger$, some preliminary experiments were made to see what effect the temperature of the gas had upon the amount of ionization produced in it. These preliminary experiments gave results which were at variance with some experiments of Prof. Perrin $\S$ published in 1897. It was therefore considered advisable to make a fresh investigation of this subject. The results of this investigation are given in the present paper.

These experiments were carried out in order to ascertain whether a change in the temperature of a gas has any effect upon the amount of ionization produced per unit volume by the action of Röntgen rays of a given intensity, and if so to determine in what way the ionization is affected by the temperature. This was tested by the method usually employed in testing ionization under different conditions, namely, by

* A preliminary account of some of these experiments was published in the Proceedings of the Cambridge Phil. Soc. vol. xii. pt. 3, May 1903.

+ Communicated by Prof. J. J. 'Thomson.

t Phil. Mag. Dec. 1903.

§ Annales de Chimie et de Pliysique, xi. p. 496 (1897).

Phil. Mag. S. 6. Vol. 7. No. 38. Feb. 1904. 
measuring the rate of leak between two metal electrodes, or sets of electrodes, when the gas between them has been ionized. For the purposes of the present experiments this had to be done at various temperatures. The gas to be experimented upon had therefore to be inclosed in a vessel which could be heated to a fairly high temperature.

When investigating air the experiments may be made in either of two ways. The first way is to inclose the air in a vessel which is not air-tight, and which will allow the air to expand freely when heated, so that the measurements may be taken in air at a constant pressure but in which the density changes as the temperature is varied. The second way is to inclose the air in an air-tight vessel so that the volume and density of the air experimented upon are kept constant at the various temperatures. In the present investigation both of these methods have been employed. A description of each, with the results obtained, will be given in turn.

\section{Experiments on Air at Constant Pressure.}

As already mentioned these experiments arose out of the investigation on the rate of recombination of ions, and the apparatus used was originally designed for the experiments on the recombination. As it was suitable for the present experiments it was therefore employed, although it was a little more elaborate than would have been really necessary for the present instance. In fact, in the course of investigating the rate of recombination one of the quantities measured was the amount of ionization, and therefore some of the results given in this paper were obtained concurrently with those on recombination.

A full description of this apparatus has already been given in the paper on recombination of ions, and diagrams showing its general arrangement and construction also appeared in that paper. It will therefore not be necessary to give a full description of the apparatus here, but a less detailed diagram may be given for reference to show the general arrangement of the apparatus. This is shown in fig. 1 .

The Röntgen-ray bulb and induction-coil were as usual inclosed in a lead-covered box, and the rays emerged through a well-defined circular orifice, $\mathrm{A}$, in the lead, and passed into the brass cylinder $\mathrm{BC}$, where they ionized the air. The bulb used was one with an automatic vacuum regulator attached. The brass cylinder $\mathrm{BC}$ was surrounded by a sheet-iron cylinder, as shown in the diagram, so that there was a uniform air-space of about $10 \mathrm{cms}$. between the two cylinders. The inclosed air was heated by means of a long Bunsen 
burner placed underneath the outside cylinder, and which ran almost the whole length of the iron cylinder. The air in the brass cylinder was thus surrounded by a jacket of heated air, and by regulating the supply of gas to the burner the

Fig. 1.

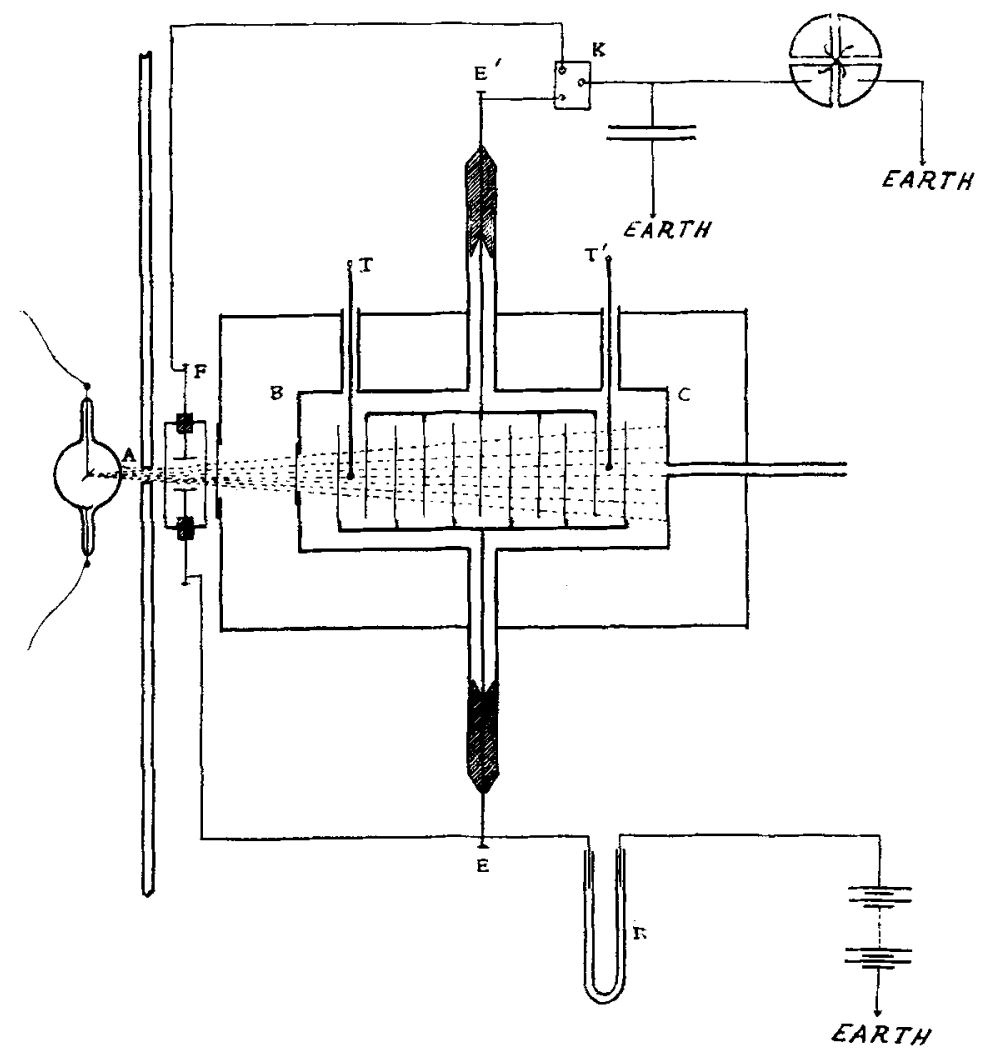

temperature of the air in the cylinder $\mathrm{BC}$ could be kept fairly constant for a considerable time. The temperature of the air was measured by the two mercury thermometers $\mathrm{T}$ and ' $\mathrm{T}$ ' shown in the diagram, and the mean of the temperatures indicated by these thermometers was taken as the average temperature of the air under investigation.

The electrode $E^{\prime}$ was connected in parallel with a condenser to one pair of quadrants of an electrometer, while the other pair was to earth. The electrometer used throughout the experiments was one of the Dolezalek type which gave about 2000 scale-divisions for a difference of potential G 2 
of one rolt between the quadrants when the needle was charged to 120 volts. The other electrode $\mathrm{E}$ was connected through a large liquid resistance $R$ to one pole of a battery of accumulators, while the other pole was to earth.

Now if the gas between two insulated electrodes be ionized by a constant source of ionization, and if to one of these electrodes a steady voltage be applied sufficiently large to extract all the ions from the gas before they have time to recombine, the other electrode will charge up at a rate proportional to the number of ions produced in the gas per second. The rate at which this electrode charges up will therefore be a measure of the amount of ionization produced in the given volume of gas per second. The deflexion of the electrometer-needle per second, which is proportional to the rate at which $\mathrm{E}^{\prime}$ charges $u p$, will be proportional to the amount of ionization prodnced in the gas, and will therefore be a measure of the amount of ionization.

To measure the ionization at different temperatures of the gas the following method was adopted. The rays were started and allowed to pass into the cylinder for an interval of five or ten seconds, so that the ionization might reach a steady state. During this interval the electrode $\mathrm{E}^{\prime}$ and the quadrants of the electrometer were comnected to earth. At the end of this time the quadrants connected to $\mathrm{E}^{\prime}$ were insulated, by a key worked at a distance by means of a cord, and were allowed to charge up for a given number of seconds, and at the end of the given time the rays were stopped and the deflexion of the electrometer-needle observed. Several readings like this were observed at the ordinary temperature of the room and the mean of these readings taken. The cylinder and inclosed air were tben heated up to a given temperature, and when the temperature became steady the deflexions were observed as before. This having been done the air was once again heated to a still higher temperature and the deflexions again observed. 'I'his was done for several temperatures up to the highest one investigated. The amount of ionization at the different temperatures could thus be compared. by comparing the deflexions obtained at these temperatures.

Instead of starting the series of readings at the lower temperature and gradually heating the air up to the higher temperatures, the order of procedure was in some cases reversed, and the air was heated up to the highest temperature to start with, and the deflexion corresponding to the ionization observed. 'The gas was then gradually cooled down from point to point, observations being taken at each temperature. Similar results were obtained in both cases. 
In making this comparison it was very essential that the source of ionization should remain constant in intensity throughout the series of observations, other wise no comparison could be made unless the amount of variation in the intensity was known. Even when using an antomatic regulating bulb it is almost impossible to obtain perfect regularity in the intensity of the rays. When taking the observations the bulb was run as far as possible at regular intervals so as to keep it steady, and also several readings were taken in each caso and the mean taken. However, even with these precautions, one cannot be certain as to whether the rays remain constant in intensity throughout the experiment unless some independentcheck is employed in order to test their constancy. For the purpose therefore of testing the constaney of the rays a small standard apparatus was introduced between the source of the rays and the large cylinder as shown in fig. 1 . It is shown in detail in fig. 2. It consisted simply of a rectangular cylinder

Fig. 2.

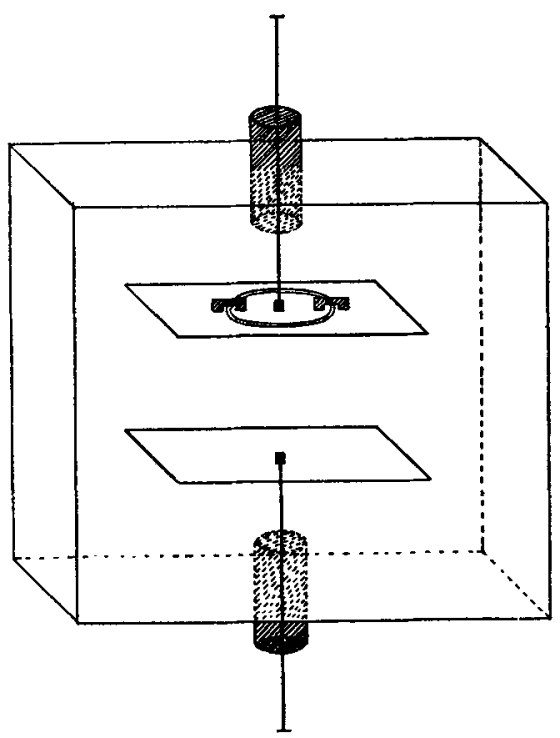

made of sheet-lead about $12.5 \mathrm{cms}$. square and $10.4 \mathrm{cms}$. in length, and the ends were covered with paper. It contained two parallel zine plates, about $9 \mathrm{cms}$. square, acting is electrodes. One of these plates was connected to the same pole of the battery as E. From the central part of the other plate was cut a circular disk $3.5 \mathrm{cms}$. in diameter, and this was 
insulated from the other part of the plate. The outer part of the plate acted as a guard-ring and was connected to earth, while the central disk could be connected to the electrometer by the key $\mathbf{K}$ when desired. The rays yassed between these plates on the way to the brass cylinder, and ionized the air between them. If the intensity of the rays remained constant the saturation-current between these plates should be constant, and any variation in the intensity of the rays should be shown by a corresponding variation in the current. After the readings had been taken on the air in the cylinder $B C$, the connexion at $K$ was transferred to the electrode $F$, and the rate of leak in the standard apparatus measured. By this means it conld be determined whether any varjation, which might occur in the rate of leak between the electrodes in the cylinder $\mathrm{BC}$, was due to a variation in the intensity of the rays or to some other cause. This therefore served as a test of the rays.

In observing the amount of ionization, as indicated by the deflexion of the electrometer-needle, it was found that as the temperature of the air increased the deflexions decreased, and that they varied in the inverse ratio to the absolute temperature. Now we must take into account here the fact that as the temperature of the air is increased its density decreases in the inverse ratio, since the gas is quite free to expand into the outside air. It was shown by Perrin * that the amount of ionization produced in a gas is proportional to the pressure of the gas, and this result was later confirmed by Rutherford and McClung $T$. Therefore, in the present instance, when the density of the gas decreases, there would be a corresponding decrease in the amount of ionization produced, due entirely to the change in density. To determine the effect on the ionization due to a change of temperature alone, a correction must be made for the change of density of the gas. In making these experiments then it was found that the decrease in the amount of ionization which took place as the temperature rose was just the amount of decrease which would occur on account of the decrease in the density of the gas, and when the necessary correction was made for the change of density no alteration in the amount of ionization was produced by the variation of the temperature itself. In other words, if the density of the gas were kept constant the amount of ionization produced by rays of given intensity would be independent of the temperature of tho gas. A series of readings is given in Table $I$. as a sample of the results which were obtained.

* Annales de Climie et de Physique, xi. p. 496 (1897).

+ Phil. Trans. cxevi. (1901). 
Ionization produced in Gases by Röntgen Rays.

TABLE I.-Air.

\begin{tabular}{|c|c|c|}
\hline \multicolumn{2}{|c|}{$\begin{array}{c}\text { Amount of Ionization as represented by Deflexions } \\
\text { of Electrometer Needle. }\end{array}$} & $\begin{array}{c}\text { Temperature } \\
\text { of }\end{array}$ \\
\hline $\begin{array}{c}\text { Observed Deflexion in } \\
\text { Scale-Divisions. }\end{array}$ & $\begin{array}{c}\text { Corrected for Change in } \\
\text { Density of Air. }\end{array}$ & Air. \\
\hline 267 & 267 & $15^{\circ} \mathrm{C}$ \\
232 & 279 & $74^{\circ}$ \\
199 & 272 & $120^{\circ}$ \\
179 & 266 & $155^{\circ}$ \\
157 & 258 & $201^{\circ}$ \\
131 & 248 & $272^{\circ}$ \\
\hline
\end{tabular}

The correction for the change in density of the air is made so that the deflexions at the higher temperatures are all reduced to the same standard as that at the lowest temperature observed.

Although the numbers in the second column are not perfectly constant yet the variation is quite within the limits of experimental error, especially when we consider the difficulty of keeping the intensity of the source of ionization constant. The maximum variation in these numbers from the mean is only about 6.5 per cent., which is really very good when working with Röntgen rays. The agreement is quite close enough to show that the apparent variation in the ionization when the temperature is raised is due entirely to the change of density of the air and not to the change in the temperature directly.

\section{Experiments on Air at Constant Density.}

After concluding the experiments just described I attacked the question by the second method mentioned at the beginning of this paper, measuring the amount of ionization produced in a volume of gas inclosed in an air-tight vessel and kept at a constant density. This method is much more definite than the first one. If the air is inclosed in an air-tight vessel then the only thing that can affect the ionization in it when the air is heated is the change of temperature itself. The question is consequently simplified by getting rid of the change of density.

Although this method simplified matters in one respect it complicated them in another, for at the very outset the difficulty arose of constructing a suitable vessel which would 
remain air-tight at the higher temperatures. There must of necessity be in the vessel some joints between different materials, and the problem of how to make these joints airtight presented considerable difficulty. Several methods of making the vessel air-tight were tried, none of which proved satisfactory until the following apparatus was evolved, which is shown in detail in fig. 3 .

Fig. 3.

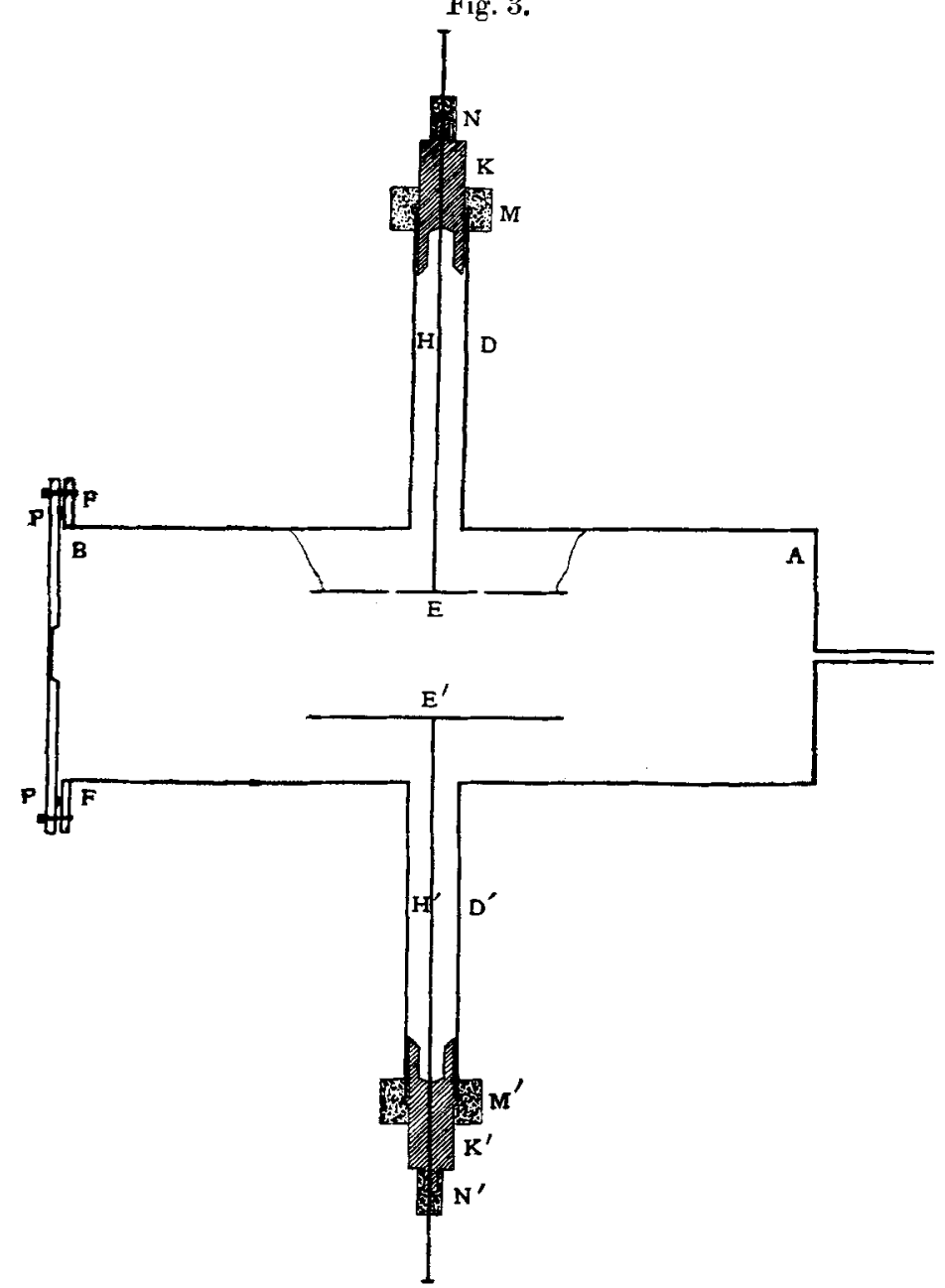

AB was a circular brass cylinder $24 \mathrm{cms}$. Iong and $7 \cdot 6 \mathrm{cms}$. in diameter. The end $A$ was joined on to the cylinder by brazing. All the brass joints were made by braxing wherever 
it was possible to do so, for solder joints were of no use, as some of the temperatures reached in the experiments were above the melting-point of solder. On the end $B$ there was brazed a heavy brass flange, as shown at $\mathrm{FF}$. PP was a thick aluminium plate $6 \mathrm{mms}$. in thickness, made so as to fit flat upon the flange. The central part of this plate was recessed to a depth of 5 mms., as shown in the diagram, so as to allow the rays to pass easily into the cylinder. To make the junction between this plate and the flange air-tight a lead wire, drawn down to a thickness of between one and two millimetres, was laid flat upon the flange, baving one end neatly overlapping the other, and then the plate $P P$ was placed flat upon this wire and tightly screwed down to the Hange, by means of strong iron screws, until the lead wire became flattened down to half its thickness or less. This joint proved very satisfactory, and was capable of withstanding any of the temperatures employed in the experiments.

$\mathrm{E}$ and $\mathrm{E}^{\prime}$ were two parallel brass plates between which the rate of leak was measured, the rays passing between them after entering at the end $B$. The plate $E$ was surrounded by a guard-ring connected to earth. These plates were supported by the heavy brass rods $\mathrm{H}$ and $\mathrm{H}^{\prime}$ which passed out through the large insulating ebonite plings $\mathrm{K}$ and $\mathrm{K}^{\prime}$. These ebonite plugs fit into the ends of the brass tubes $\mathrm{D}$ and $\mathrm{D}^{\prime}$, and these tubes were made of considerable length so that the insulation might be removed as far as was convenient from the cylinder which was to be heated. To make the junctions between the ebonite plugs and the brass tubes air-tight large rubber corks $\mathrm{M}$ and $\mathrm{M}^{\prime}$ were bored to fit tightly over them, and then they were bound round tightly with heary wire. A similar joint was made at $\mathrm{N}$ and $\mathrm{N}^{\prime}$ by means of heavy rubber compression-tubing. These junctions also proved very satisfactory.

The cylinder and the inclosed gas were heated by means of an electric current passing through a coil of german-silver wire wound tightly round the outside of the cylinder, and insulated from the cylinder by means of sheet-asbestos. By this means the gas in the cylinder could be heated up fairly quickly, and by regulating the current the temperature of the gas could be kept quite steady. The temperature of the gas was measured by means of a mercury pressure-gauge $k$ connected to the tube T, as shown in the diagram in fig. 4, where the general arrangement of the apparatus is shown. The increase in temperature, as indicated by the expansion of the gas, was measured by the height to which the mercury in the arm $L$ rose above a fixed point $Q$. The mercury in 
the arm $Q$ could always be brought back to the same point by adjusting the height of the mercury reservoir $S$, and the gas in the cylinder could thus be kept at a constant volume

Fig. 4.

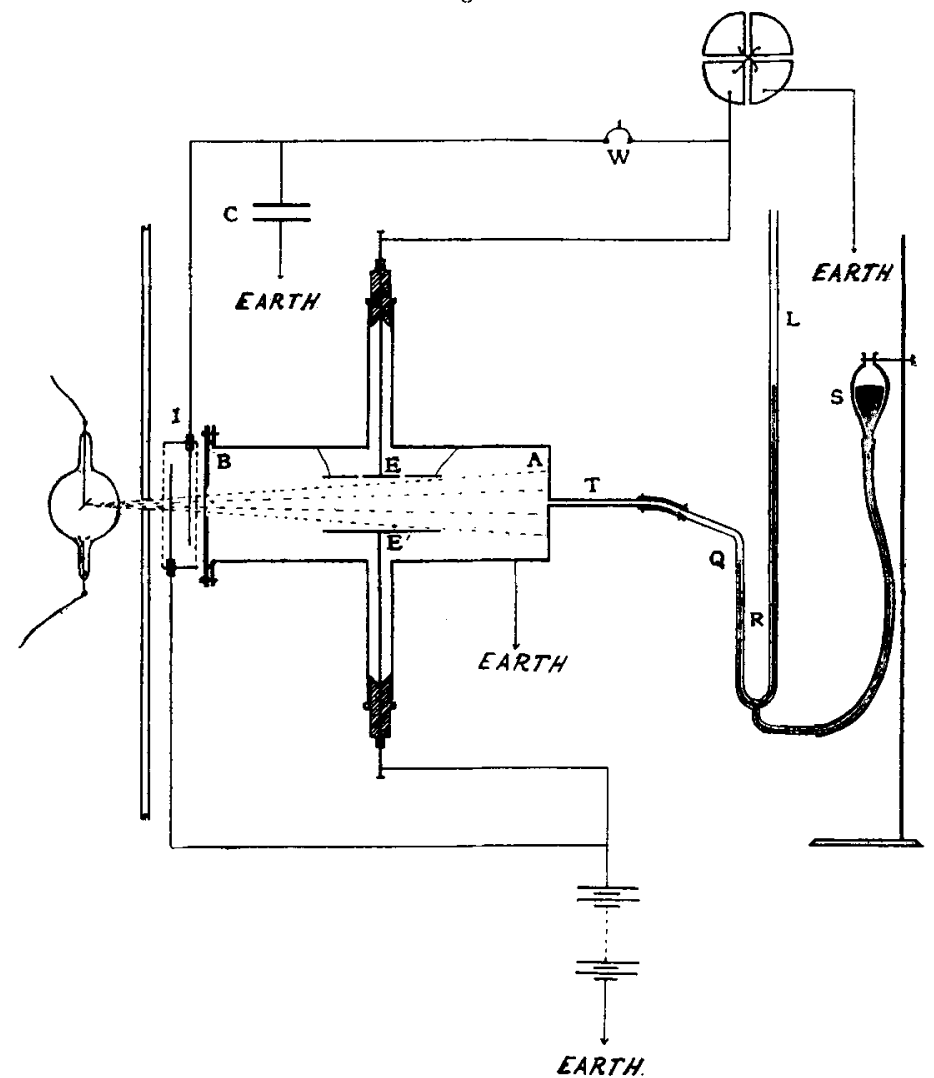

and density. Measuring the temperature by this method obviated the necessity of inserting a mercury thermometer into the vessel, and thereby the number of air-tight junctions to be made was lessened.

The manner of taking observations was somewhat similar to that already described in the first method. In some cases the ionization was measured at the ordinary temperature of the room, and then the gas was gradually heated up from point to point. In other cases the reverse order was followed and the ionization was measured at the highest temperature first and the gas then gradually corled down, and measurements taken at the various temperatures. 
Ionization produced in Gases by Röntgen Rays.

A slightly different form of standard apparatus for testing the intensity of the rays was used in this case also. A diagram of it is shown in fig. 5. The electrodes in this Fig. 5.

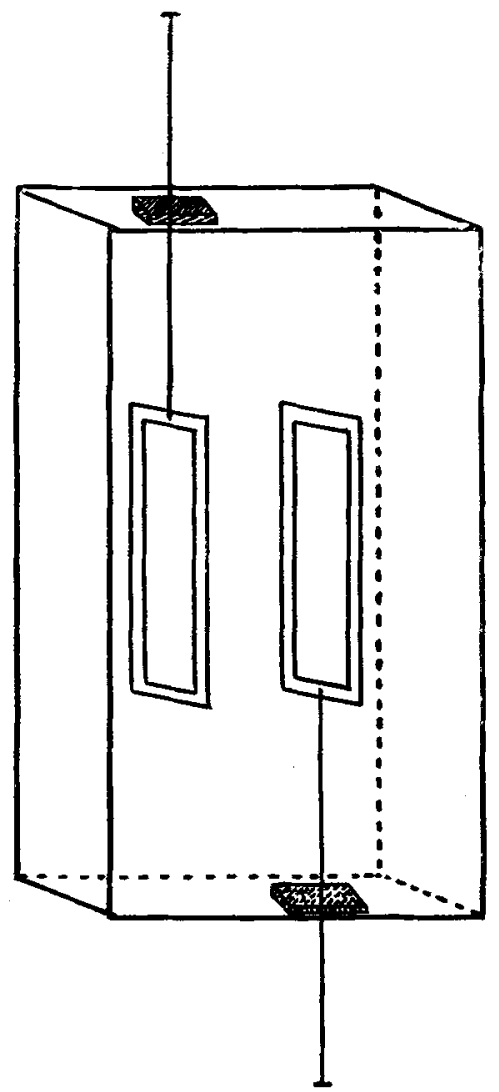

case consisted of extremely thin aluminium foil stretched on copper frames, and the rays passed through at right-angles to the plane of the foil. This form was adopted in order that the standard apparatus might be made to occupy less space, so that the cylinder might be placed as close up to the source of rays as possible. This standard apparatus was arranged as shown in fig. 4. One electrode was connected to the same pole of the battery as the electrode $\mathbf{E}^{\prime}$. The other electrode was connected in parallel with a condenser $\mathrm{C}$ through a key $\mathrm{W}$ to the electrometer. This key was worked at a distance by means of a cord, and could be opened at the same instant as the key by which $\mathrm{E}$ was insulated. 
In taking the observations the rars were started and allowed to run for a definite number of seconds, so that the ionization might reach a steady state, both the electrodes $\mathbf{E}$ and I being: to earth daring this time. At the end of this interval the electrode $\mathrm{E}$ was insulated and the key $\mathrm{W}$ opened simultaneously, and the rays were allowed to run for a given time. The electrodes $E$ and I were thus allowed to charge up for exactly the same time, and under the influence of the same cone of rays. The reading of the electrometer corresponding to the charge on $\mathbf{E}$ was observed, and then the quadrants of the electrometer were discharged and again insulated, and the key W was then closed and the deflexion corresponding to the charge on I observed. This served therefore as a very close check on the constancy of the rays during exactly the same time as the measurements were being made in the cylinder AB.

The first gas tested with this apparatus was of course air, in order to see if the results would be in agreement with the previous experiments. Observations were taken over a range of temperature of nearly $200^{\circ} \mathrm{C}$, and the results obtained exactly confirmed the previous results which I had obtained. In this case when the density of the air was kept constimi, the amount of ionization also remained constant. The change of temperature of the air had no effect whatever upon the amount of ionization produced in it. A set of results obtained is shown in Table II. as a specimen.

TABLE 11.-Air.

\begin{tabular}{|c|c|c|}
\hline $\begin{array}{c}\text { Ionization as represented } \\
\text { by Scale-Divisione for } \\
\text { the Cylinder A B. }\end{array}$ & $\begin{array}{c}\text { Ionization as represented } \\
\text { by Scale-Divisions for } \\
\text { Standard Apparatus. }\end{array}$ & $\begin{array}{c}\text { Temperature of } \\
\text { Air in } \\
\text { Cylinder AB. }\end{array}$ \\
\hline $83 \cdot 7$ & $27 \cdot 0$ & $201^{\circ} \mathrm{C}$. \\
$86 \cdot 5$ & $30 \cdot 3$ & $10^{\circ}$ \\
$82 \cdot 8$ & $27 \cdot 7$ & $118^{\circ}$ \\
$85 \cdot 8$ & $31 \cdot 5$ & $87^{\circ}$ \\
$80 \cdot 4$ & $28 \cdot 5$ & $45^{\circ}$ \\
$83 \cdot 2$ & $28 \cdot 5$ & $14^{\circ}$ \\
\hline
\end{tabular}

From the results obtained therefore by the two methods there appears to be no doubt whatever that, when the density of a given volume of air is kept constant, the amount of ionization produced in it per second by rays of a given intensity is quite independent of the temperature of the air. 
Measurements on Carbon Dioxide and Hydrogen.

The next gas experimented upon was carbon dioxide. It was treated in exactly the same manner as air had been. It was prepared in the ordinary way by the action of pure hydrochloric acid on marble, and was dried by passing it over pumice-stone moistened with strong sulphuric acid before it entered the cylinder. The results obtained with this gas were quite in accordance with those obtained for air. Observations were taken over an even greater range of temperatures than in the case of air, and the same law was found to hold with the carbon dioxide as was shown to hold in air. A series of results for this gas is shown in Table IIr.

TabLe III.-Carbon Dioxide.

\begin{tabular}{|c|c|c|}
\hline $\begin{array}{c}\text { Ionization as represented } \\
\text { by Scale-Divisions for } \\
\text { the Cylinder AB } \\
\text { filled with CO.2. }\end{array}$ & $\begin{array}{c}\text { Ionization as represented } \\
\text { by Seale-Dirisions for } \\
\text { Standard Apparatus. }\end{array}$ & $\begin{array}{c}\text { Temperature of } \\
\mathrm{CO}_{2} \text { in } \\
\mathrm{Cylinder}^{\mathrm{AB}}\end{array}$ \\
\hline $80 \cdot 1$ & $24 \cdot 9$ & $222^{\circ} \mathrm{C}$ \\
$84 \cdot 4$ & $25 \cdot 1$ & $182^{\circ}$ \\
82.0 & $25 \cdot 2$ & $146^{\circ}$ \\
$79 \cdot 1$ & $24 \cdot 6$ & $108^{\circ}$ \\
$83 \cdot 8$ & 26.2 & $69^{\circ}$ \\
$87 \cdot 1$ & $25 \cdot 3$ & $17^{\circ}$ \\
\hline
\end{tabular}

A considerable number of experiments were also made on hydrogen. It was found very difficult to obtain really satisfactory results with hydrogen on account of the great difficulty experienced in making the cylinder perfectly gastight for this gas. The joints which proved so satisfactory in the case of air and carbon dioxide gas did not serve the purpose so well in the case of hydrogen, on account of the greater ease with which it diffuses, and I was consequently never able to make the vessel perfectly gas-tight for hydrogen. The difficnlty was also increased by the fact that the amount of ionization produced in hydrogen is so much smaller than in the other gas, and therefore the effect to be measured was much smaller. Consequently the results obtained for hydrogen were not so accurate as those obtained in the case of air and carbon dioxide. However, taking the results as a whole, I think we may conclude that the same law holds for hydrogen as holds in other cases. Table IV. contains a set of results obtained for hydrogen. 
94 Effect of Temperature on Ionization by Röntgen Rays. TABLE IV.-Hydrogen.

\begin{tabular}{|c|c|c|}
\hline $\begin{array}{l}\text { Ionization as represented } \\
\text { by Scale. Divisions for } \\
\text { the Cylinder } A B \\
\text { filled with } \mathrm{H}_{2^{*}}\end{array}$ & $\begin{array}{l}\text { Ionization as represented } \\
\text { by Seale-Divisions for } \\
\text { Standard Appuratus. }\end{array}$ & $\begin{array}{c}\text { Temperature of } \\
\mathrm{H}_{2} \text { in } \\
\text { Cylinder } \mathrm{AB} .\end{array}$ \\
\hline 89 & 299 & $296^{\circ} \mathrm{C}$ (approx.) \\
\hline 96 & 295 & $187^{\circ} \quad "$ \\
\hline 88 & 302 & $148^{\circ}$ \\
\hline 78.9 & 304 & $112^{\circ}$ \\
\hline 799 & 295 & $78^{\circ}$ \\
\hline $66 \cdot 7$ & 384 & $14^{\circ}$ \\
\hline
\end{tabular}

Although there is considerable variation in the above numbers, still I think this want of constancy can be accounted for chiefly by the leakage in the vessel. However, from all the results obtained, I think we may safely conclude that hydrogen follows the same law for the effect of temperature on the ionization as has been established for air and carbon dioxide.

\section{Discussion of Results.}

The experiments described in this paper have proved conelusively that in a given volume of gas, kept at a constant density, the amount of ionization produced by Röntgen rays of a given intensity is independent of the temperature of the gas. Prof. Perrin, in the paper to which reference has already been made at the beginning of this paper, described some experiments which he made on this same question. The results which he obtained are, however, not in agreement with those which I have just given in this paper. The method which he employed was a differential one. He made the rays to pass simultaneously between two sets of parallel plates. He then balanced the effect produced on one set of electrodes against that produced on the other set, so that the resultant effect produced on the electrometer was zero. This balance was adjusted at a certain temperature, and then the temperature of the gas in the vessel containing one set of plates was varied and the balance then tested. For the range of temperature from $-12^{\circ}$ to $148^{\circ} \mathrm{C}$. he found no appreciable alteration in the balance. He concludes therefore that, since no change in the balance occurred and the density of the air varied incersely as the absolute temperature, the total ionization would be proportional to the absolute temperature in air maintained at a constant density. I cannot account with 
The Arc in Metallie Vapours in an Exhausted Space.

certainty for the discrepancy between his results and those which I obtained, but I think it probable that the apparatus which he used may not have been sensitive enough to detect the alteration in the ionization. $\mathrm{He}$ mentions that at the higher temperatures the "heated vessel appeared less active," but attributed this to some other cause. It looks extremely probable that this was a genuine effect, but that the detecting instrument was not sensitive enough to show the effect to a sufficiently great extent. In the experiments which I did the electrometer used was a very sensitive one, giving a deflexion of about two thousand scale-divisions for a difference of potential of one volt between the quadrants. There was therefore no difficulty in detecting any alteration that might take place in the ionization.

In conclusion I desire to express my thanks to Prof. Thomson for the kindly interest shown and adrice given throughout the course of this investigation.

Cavendish Laboratory,

Cambridge, Nov. 5th, 1903.

XII. Investigation of the Arc in Metallic Vapours in an Exhausted Space. (Contribution from the Research Laboratory of General Electric Co., Schenectady, N.Y.) By E. Weintraub, Ph.D.*

[Plates III.-XI.]

\section{Introduction.}

WHILE the earbon arc has been the object of a great number of investigations, the are between mercury electrodes, which offers much simpler relations from a theoretical point of view, has so far been investigated but very little. We may distinguish between two distinct periods. In the first one the investigation was limited to the mercury arc in air. Thomas Way (1857), (18b1) $\dagger$ was probably the first to publish observations on a mercury arc in air. One of his electrodes consisted of a stream of mercury, the second one of a mass of mercury or a piece of carbon, upon which the stream was caused to flow.

Beginning at that time, a number of inventors occupied themselves with the arc, and a great number of patents were taken out on this subject. They were all founded on the same principle as the lamp of Way, and did not contribute anything essentially new to the art or science.

* Communicated by the Author.

† Dingler's Polytechn. Journ. vol. clvii. p. 399 (1860); vol. clix. p. 46 (1861); also U.S. Pat. 3345, Oct. 8 (1861); Eng. Pat. 2841 (1857). 